Est Ag 43 (2008) 389-392

\title{
La nueva y obsesiva religión del cuerpo
}

Dicen algunos sociólogos que en el último siglo se ha producido uno de los cambios de paradigmas más transcendentales en la sociedad occidental. Algo que no tiene mucho que ver con la ciencia o la técnica, sino con las creencias, aspiraciones y sentimientos más profundos de la gente, algo relativo a lo que conocemos como "religión". En síntesis, el cambio producido es el siguiente: la preocupación por el alma ha sido sustituida por la preocupación por el cuerpo. Esto, traducido a la vida cotidiana, significa la sustitución de los miedos ancestrales de la humanidad relativos al espíritu (en la religión cristiana, expresados en el miedo al pecado, a la condenación, al demonio y al infierno) con aquellos relativos al cuerpo y al estado de salud.

Definitivamente, la obsesión por la salud y la apariencia del cuerpo es una de las características más destacadas de la cultura moderna occidental. El hombre, que no puede vivir sin un referente trascendente o, lo que algunos llaman, sin una religión, ha sustituido los viejos dioses, santos y devociones por unos nuevos, si bien más laicos y menos "trascendentes".

Efectivamente, hace apenas medio siglo, la religiosidad, entendida como vinculación con lo trascendente y lo espiritual, inundaba casi todos los aspectos de las sociedades occidentales, como todavía inunda a ciertas sociedades orientales. Dependiendo de culturas y sociedades, en algunas el cambio se ha producido antes y en otras después. El estado del espíritu y la moral ("estar en pecado" o "estar en gracia de Dios") eran los grandes dilemas del cristiano. El cristianismo de esa época (y, en ciertas corrientes cristianas, si bien minoritarias, todavía de ahora) ponía mucho énfasis en los temas relacionados con el pecado y la salvación o condenación del alma. El miedo al diablo y al infierno (y como consecuencia, al pecado, causa de la condenación) era quizás el más dominante entre la gente. 
La secularización que han sufrido estas sociedades en estas últimas décadas ha ido relegando al rincón de los recuerdos a las creencias religiosas: hoy la asistencia a las iglesias en muchos países de Europa está por debajo del 20 ó 30\%, en comparación con el 70 u 80\% de hace apenas medio siglo. Los practicantes de la religión son cada vez más los adultos y ancianos de generaciones pasadas, pero los jóvenes son cada vez más los grandes ausentes de las iglesias. Estados Unidos, donde el desarrollo económico no ha ido paralelo con el desarrollo cultural de grandes sectores de su población, es quizás la excepción, por el gran poder que las sectas protestantes fundamentalistas todavía tienen, sobre todo el llamado "cinturón de la Biblia" de los estados del centro.

\section{El surgimiento de la nueva religión del cuerpo}

Hace unas décadas, el tema de salud, nutrición y el estar en forma ("fitness", para los devotos extremos del culto a la corporeidad) apenas ocupaban en los medios de comunicación espacios marginales o eran simplemente temas de noticia de tercera página. Hoy los medios escritos y los programas televisivos y radiales dedicados a la nueva religión del cuerpo son legión. Ni hablar de la publicidad del sin fin de productos, medicinales, alimenticios, deportivos o de gimnasia.

Los jóvenes de antes no se preocupaban de la salud o de la nutrición a no ser que sufriesen una enfermedad seria. Hoy, las nuevas hordas de personajes "light" (desde metro-sexuales hasta aspirantes fracasadas a top models) están tan obsesionados con la salud y estado de forma del cuerpo que el espejo, la báscula, el agua embotellada, los re-hidratantes light, las cremas para la piel, los desodorantes, los maquillajes, los nutricéuticos, y los alimentos orgánicos e integrales son los nuevos instrumentos religiosos en reemplazo del agua bendita, la hostia, el incienso y las velas.

Las clínicas de cirugía estética, los gimnasios, los salones de belleza, los "spa" y otras instalaciones deportivas, de belleza y salud han sustituido a las iglesias y santuarios, y la parafernalia deportiva y de gimnasia (la increíble variedad de ropas, equipos y accesorios) ha sustituido a escapularios, reliquias, estampitas, rosarios, medallas, hábitos y otros implementos religiosos. Satanás y el pecado son ahora el sobrepeso, los alimentos ricos en calorías, el colesterol, los triglicéridos, la celulitis, las arrugas, la vejez, y otras fobias modernas relativas al cuerpo.

Los dogmas de fe antiguos han sido sustituidos por "estar en forma", la "línea" y el peso corporal perfecto, la dieta perfecta, el cutis perfecto y los bajos índices de colesterol y de triglicéridos. Los santos y vírgenes, 
modelos de las generaciones antiguas, han sido sustituidos por las top models, los deportistas, los cantantes y los artistas de cine o televisión, todos con caras y cuerpos perfectos. El culto a la santidad (personas en las que primaban los valores espirituales, al margen de edad o estado o apariencia física) ha sido sustituido por el culto a la juventud, a la belleza física y a la corporeidad.

El espíritu aquí es secundario. Hubo un tiempo en el que la gente admiraba y exaltaba no sólo los méritos y cualidades de los santos, sino las de los poetas, talentos de las artes plásticas, filósofos o sabios en general. Baste leer las tradiciones de Ricardo Palma para verificar quiénes eran los héroes de Lima hace siglo y medio o dos siglos: los ganadores de las justas poéticas, los abades de los conventos y los predicadores "pico de oro" estaban en el centro de la actividad social. Hoy, el músculo, el perfil francés, el bronceado del Caribe, la cintura, el trasero o el busto se convierten en las cualidades más admiradas y envidiadas por un gran sector de las nuevas generaciones en muchos de los ídolos modernos.

\section{La trivialidad de los nuevos dogmas}

La fragilidad de los nuevos dogmas de la religión del cuerpo se manifiesta en su precariedad: según un reciente estudio realizado en EE.UU., el promedio de años que dura un consejo médico (relativo a un medicamento, alimento o nutricéutico) antes de ser sustituido por otro es de apenas cinco años. Lo que antes era malo (como el pescado azul, los huevos o los embutidos de cerdo) resulta que ahora es bueno, y viceversa.

Pero esto no les importa mucho a los millones de devotos de la nueva religión. Lo que sí está más que asegurado es que, si alguien quisiera seguir a rajatabla todos los consejos sobre dietas, hábitos de consumo, y medicamentos "maravillosos" para el bienestar del cuerpo se volvería auténticamente loco y, seguramente, podría en serio riesgo su salud.

La autoridad de los oficiantes de la nueva religión son un pálido reflejo de las antiguas: los nutricionistas, estilistas, cirujanos estéticos, masajistas, entrenadores personales ("personal trainers", para los iniciados en el culto) han sustituido a los curas, confesores y asesores espirituales. Las posesiones diabólicas han sido sustituidas por enfermedades modernas como la anorexia y la bulimia, y los apestados de antes (los "pecadores" públicos, como prostitutas, libertinos y ateos) han sido sustituidos por los obesos, los feos de misericordia, y los viejos en general. Parafraseando a los fascistas de los años 40, el nuevo lema de las generaciones modernas parecería ser: "¡Viva el cuerpo, y muera el espíritu”! 
Está más que claro que la liberación de las opresivas cadenas de la religión, proclamada y aclamada por tantos ilustrados, agnósticos y neoliberales, en realidad no es tal: simplemente han sido sustituidas por otras más ramplonas y mundanas, pero no menos esclavizadoras y, para preocupación de muchos, mucho más caras: los elementos del "culto" de la nueva religión cuestan mucho más que los del antiguo.

La nueva religión, al contrario de la antigua, que se veía reducida en la mayoría de los casos a espacios (iglesias) y tiempos (domingos y fechas religiosas) hoy invade hasta los más recónditos espacios de la vida de las personas. El espejo y la balanza han sustituido al confesonario, y se han metido en casa.

Dicen que sarna con gusto no pica, pero esta sarna sí que pica, y si por unas arrugas, unos kilitos de más y una curva imperfecta en la cintura o en el trasero la gente sufre torturas inimaginables, llegando a situaciones auténticamente patológicas y comportamientos totalmente autodestructivos, nos podemos imaginar lo que pasa con la gente que ha puesto todo su corazón, no en un tesoro material (como dice el cada vez más olvidado Evangelio), sino en la apariencia de un cuerpo marchitable y perecible, cuando éste envejece...

Ése, sin duda, es el infierno de la nueva religión... ¿Alguien conoce, sin embargo, dónde está su cielo?... 